MEI

II, vol. 5 $n^{\circ} 8$

\title{
El archivo audiovisual de Radiotelevisión Valenciana como archivo histórico. Propuestas de actuación.
}

\author{
Concha Soler Monreal
}

\begin{abstract}
Resumen
El objetivo de este trabajo es proponer actuaciones para la salvaguarda y difusión del patrimonio audiovisual valenciano. Se plantea que el archivo de Radiotelevisión Valenciana sea el germen de un futuro archivo audiovisual de la Comunidad Valenciana mediante la incorporación de fondos a través del depósito legal y el número ISAN, la recopilación de webseries y otros materiales difundidos en la Red producidos en la Comunidad Valenciana, y la posibilidad de custodiar materiales de emisoras de televisión y radiodifusión de carácter local y/ o autonómico. De este modo se consigue que el archivo de RTVV se mantenga vivo tras el cese de actividad de la cadena, explotando su valor comercial y difundiendo sus contenidos a la vez que se custodia y se garantiza su preservación.
\end{abstract}

\section{Palabras clave}

Archivos audiovisuales; Patrimonio audiovisual; Depósito legal; Producciones audiovisuales; Archivos de televisión; Preservación; Acceso público.

The audiovisual archive Broadcasting Valencia as a historical archive. Proposals for action

Abstract

The aim of this paper is to suggest actions to safeguard the Valencian audiovisual heritage. Using the Radiotelevisión Valenciana archive, we propose the inclusion of audiovisual collections through legal deposit for productions in the Valencian Community, as well as the inclusion of webseries and other materials produced in Valencian Community and disseminated on the Internet. In addition, we also propose the archive guards materials of local and regional television broadcast channels. The proposals ensure the archive will be kept alive, by exploiting its market value and disseminating its contents while custody and preservation are guaranteed.

\section{Keywords}

Audiovisual archives; Audiovisual heritage; Legal deposit; Audiovisual productions; Television archives; Preservation; Public Access.

\section{1.-Introducción}

El reciente cierre de Radiotelevisión Valenciana (RTVV) trae como consecuencia inmediata para sus fondos documentales que dejen de ser archivos corrientes. Si su finalidad principal era la de servir a la empresa en la que se integraba ahora será principalmente un archivo cuyo activo principal estará formado por el fondo audiovisual (sin olvidar el archivo de prensa, la hemeroteca, la 
biblioteca y la discoteca) pero cuyo objetivo principal será la preservación de sus contenidos.

No vamos a entrar en la obligación, avalada por diversas leyes estatales y autonómicas, de conservar los estos materiales, pero sí haremos hincapié en distintas recomendaciones internacionales para la salvaguarda del patrimonio audiovisual. Las imágenes en movimiento constituyen un bien intangible e inmaterial junto con el valor añadido otorgado por el documentalista en las bases de datos, lo que las hace recuperables para usos futuros.

Las Recomendaciones de la Unesco para la salvaguarda del Patrimonio Audiovisual, aprobadas en la Conferencia General de la Unesco el 27 de octubre de 1980 dicen:

"Todas las imágenes en movimiento de producción nacional deberían ser consideradas por los Estados Miembros como parte integrante de su "patrimonio de imágenes en movimiento". Las imágenes en movimiento de producción original extranjera pueden formar parte también del patrimonio cultural de un determinado país cuando revistan particular importancia nacional desde el punto de vista de la cultura o de la historia de dicho país. Si la transmisión de la totalidad de ese patrimonio a las generaciones futuras no fuera posible por razones técnicas o financieras, se debería salvaguardar y conservar la mayor parte posible. Se deberían tomar las medidas necesarias para concertar la acción de todos los organismos públicos y privados interesados, con objeto de formular y aplicar una política activa con este fin".

La necesidad de preservarlos contenidos, junto a la evolución tecnológica, hacen imprescindible la digitalización de las imágenes para garantizar su conservación. La preservación adquiere sentido solamente cuando se realiza con el fin último de la difusión de los contenidos custodiados. Como dice Edmonson (2009) preservar no significa transferir de formato ni digitalizar sino evitar que se pierda "cualquier información física, audiovisual o sónica, ya que una vez se pierde información ya no se podrá recuperar".

Como señalan Hernández Pérez y Caridad Sebastián (2011) la preservación y el acceso van íntimamente unidos, ya que se preserva para garantizar el acceso pero a su vez éste debe evitar el deterioro del documento original.

Volviendo a Edmonson (2009) “...hay un factor que hemos dado por hecho en las actividades de preservación, para analógico y digital, asumimos que nuestras instituciones son estables y tendrán continuidad; sin ello, estamos a merced de la suerte y la preservación no tiene lugar”.

Veamos cómo podemos proteger un patrimonio único, memoria colectiva de 
una sociedad, generado por una institución pública que, pese a las advertencias de Edmonson, ha cesado su actividad y de la cual se desconoce su futuro.

\section{2.- Protección del patrimonio audiovisual}

La Unesco, en el punto 9 de sus Recomendaciones para la salvaguarda del Patrimonio Audiovisual (1980) recomienda la instalación de un depósito legal nacional para las imágenes en movimiento:

"Para conseguir que las imágenes en movimiento que forman parte del patrimonio cultural de los países sean sistemáticamente conservadas, se invita a los Estados Miembros a adoptar medidas en virtud de las cuales las instituciones de archivo oficialmente reconocidas puedan disponer para su salvaguardia y conservación de una parte o la totalidad de la producción nacional del país. Dichas medidas podrían consistir, por ejemplo, en acuerdos voluntarios con los titulares de derechos para el depósito de las imágenes en movimiento, la adquisición de las imágenes en movimiento por medio de compra o donación, o la creación de sistemas de depósito legal por medio de medidas legislativas o administrativas apropiadas”.

Países como Francia, Suecia y Noruega cuentan con leyes de depósito legal que protegen el patrimonio televisivo. Gran Bretaña, Suiza, Canadá y Estados Unidos, sin una legislación en este sentido, poseen acuerdos que permiten recoger y guardar las grabaciones audiovisuales.

En Francia, el INA,Institutnational de l'audiovisuel, es el depositario de los documentos audiovisuales radiodifundidos o teledifundidos y la web media. Los programas de televisión y radio de 120 emisoras públicas y privadas se recogen en formato digital a través de redes de satélites y fibra óptica, mientras que los programas audiovisuales de la web se guardan de acuerdo con un proceso que tiene en cuenta la dimensión temporal y cuantitativa de los sitios web relacionados con material audiovisual. Los programas están a disposición de investigadores, profesionales, artistas, docentes en la sede del INA y en una red de centros territoriales.

La producción audiovisual sueca es regogida por el StatensLjud- ochBildarkiv (SwedishNational Archive of RecordedSound and Moving Images) o SLBA, un archivo estatal que obliga por la ley de depósito legal de 1979 a guardar las grabaciones de programas emisoras de televisión y radio. Según dice su página web, probablemente Suecia es el primer país que destacó la importancia de los medios audiovisuales como material para la investigación.

Por su parte, Noruega, cuenta con una ley de depósito legal que obliga a los canales de televisión y radio de cobertura nacional a entregar una copia de sus programas a la Biblioteca Nacional. 
En Suiza no existe una legislación nacional para el depósito legal aunque algunos cantones sí cuentan con normativa al respecto. La asociación Memoria v (formada por la Biblioteca Nacional Suiza, Los Archivos Federales Suizos, la Fonoteca Nacional Suiza, la Cinemateca Suiza, la Sociedad Suiza de Radiodifusión, la Oficina Federal de la Comunicación y el Instituto Suizo para la Conservación de la Fotografía) se encarga desde 1995 de la custodia y tratamiento del patrimonio audiovisual suizo. Las actividades de Memoria v están avaladas por la loi sur l'encouragement de la culture, actualmente en vigor para el periodo 2012-2015.

Sin contar con una ley específica de depósito legal, en la práctica la Biblioteca del Congreso de los Estados Unidos realiza esta función a través del registro de la propiedad intelectual. Hasta la década de 70 los precios que debían pagar los productores para registrar sus obras eran elevados, lo que provocó que algunas colecciones estén incompletas. Por otro lado, como señala Ronco (2009) las grandes cadenas de televisión entregan copia de sus documentos de actualidad a los Archivos Nacionales.

Las emisoras de televisión terrestres de Gran Bretaña están obligadas a archivar sus productos según la Ley de Radiodifusión (BroadcastingAct) de 1990. Los programas de televisión son conservados por la BBC y el National Film and Television Archive, integrado en el British Film Insititute, BFI. En 1997 el grupo de trabajo de depósito legal de la Biblioteca Británica se hizo eco de la opinión del BFI, que considera que las producciones audiovisuales deben formar parte de un sistema integral de depósito legal.

En Canadá, las encargadas de seleccionar documentos audiovisuales son las Bibliotecas y Archivos Nacionales.

En el resto de países de nuestro entorno, son las propias empresas y organismos de televisión los encargados de la conservación de los archivos audiovisuales: RAI (Italia), ZDF (Alemania), ORF (Austria), RTP (Portugal), etc. (Hidalgo, 2013).

Por lo que respecta a España, la antigua ley de depósito legal no hacía referencia a las producciones audiovisuales pero sí lo hace la más reciente. La entrada en vigor de la ley 23/2011 de depósito legal desarrolla la obligación de conservar publicaciones "no tangibles". Es más, la ley dice en su capítulo 1 que la verdadera finalidad del depósito legal es la "reunión, conservación y difusión de las publicaciones del patrimonio bibliográfico, sonoro, visual, audiovisual y digital de las culturas de España en cada momento histórico, y permitir el acceso al mismo con fines culturales, de investigación o información, y de reedición de obras, de conformidad con lo dispuesto en esta ley y en la 
legislación sobre propiedad intelectual.”

El ámbito de la ley se extiende a los sitios web y cualquier otro tipo de publicaciones electrónicas que se puedan desarrollar en el futuro y se establece que serán los centros conservadores designados por las Comunidades Autónomas y la Biblioteca Nacional de España los responsables de archivar los contenidos web. De hecho, la Biblioteca Nacional realiza esta actividad desde el año 2009, en colaboración con Internet Archive, rastreando todos los dominios .es. El borrador del proyecto de real decreto por el que se regula el depósito legal de las publicaciones electrónicas hace referencia explícitamente al patrimonio audiovisual electrónico en su artículo 1:

"El presente real decreto tiene por objeto regular el procedimiento de gestión del depósito legal de las publicaciones electrónicas, con la finalidad de cumplir con el deber de preservar el patrimonio bibliográfico, sonoro, visual, audiovisual y digital de las culturas de España en cada momento histórico y permitir el acceso al mismo con fines culturales, de investigación o información, de conformidad con lo dispuesto en la Ley 23/2011, de 29 de julio, de depósito legal, así como en la legislación sobre protección de datos y propiedad intelectual."

Además, según establece la ley 17/2006, de 5 de junio, de la radio y la televisión de titularidad estatal se dice que la corporación RTVE debe velar por la conservación de los archivos históricos audiovisuales.

En el caso de Radiotelevisión Valenciana, ni la ley de creación de 1984 ni la posterior ley 3/2012, de 20 de julio, de Estatuto de Radiotelevisión Valenciana (ambas derogadas) hacían referencia a los fondos documentales excepto una instrucción aprobada por el director General en 2002, que mencionaba la preservación y el acceso a los mismos.

Por lo que respecta a las cadenas de televisión privadas, hasta no hace mucho, solamente estaban obligadas a guardar una copia de su emisión durante seis meses (la llamada “copia legal”), según establece la Ley de televisiones privadas (Ley 10/1988 de 3 de mayo), si bien la ley General de la Comunicación Audiovisual, 7/2010, que deroga a la anterior, en su disposición adicional sexta dice que "los operadores de comunicación audiovisual estarán obligados a preservar y a conservar el archivo de imágenes en movimiento y audio". En el mismo sentido, la Ley de Patrimonio Histórico, en su artículo 52.1 dice que "todos los poseedores de bienes del Patrimonio Documental y Bibliográfico están obligados a conservarlos, protegerlos, destinarlos a un uso que no impida su conservación y mantenerlos en lugares adecuados”. 


\section{3.-Propuestas de actuación de un archivo histórico audiovisual de la Comunidad Valenciana.}

El cierre de Radiotelevisión Valenciana trae consigo una situación inédita, ya que, aunque no es la primera empresa televisiva que deja de emitir, sí es la primera cadena pública que lo hace en nuestro país.

Este hecho obliga a reflexionar sobre la situación en la que queda el mayor fondo documental centrado en la Comunidad Valenciana de la historia reciente de los últimos 25 años.

En este sentido, las recomendaciones de la Unesco (1980) dicen que :

"Se debería facilitar el más amplio acceso posible a las obras y fuentes de información que representan las imágenes en movimiento adquiridas, salvaguardadas y conservadas por instituciones públicas o privadas de carácter no lucrativo".

Para garantizar la preservación de los fondos y al mismo tiempo ponerlos a disposición de los ciudadanos, la tecnología actual nos permite la digitalización de las imágenes, aunque requiere inversión en medios técnicos y humanos. Este proceso permitiría operar con versiones digitales para el visionado y conservar las grabaciones en cinta en un archivo definitivo.

Ya que Radiotelevisión Valenciana se creó con fondos públicos debe estar accesible a los ciudadanos, y para ello se propone la creación de una página web donde se puedan visionar materiales en baja resolución y donde se puedan realizar búsquedas online sobre las bases de datos referenciales.

Dicho catálogo serviría para dar servicio a tres clases de usuarios:

1. Investigadores, docentes, profesionales y estudiantes previa acreditación. A este grupo se le debería facilitar el acceso para la consulta física de materiales de producciones propias. También se les podría permitir el visionado de materiales de los que no se tienen derechos, que no se pueden difundir, ni copiar.

2. La explotación comercial sirviendo copias de producciones de material propio a organizaciones privadas, empresas y particulares.

3. Ciudadanos en general que deseen consultar emisiones de producción propia podrían hacerlo a través de la web (con marcas de agua y otros dispositivos anticopia).

El servicio público se completaría con: 
-Copias en formato doméstico para centros educativos públicos.

La hemeroteca, única por su alcance y contenido en la Comunidad Valenciana, ayuda a comprender y a situar en su contexto las imágenes contenidas en el fondo audiovisual, que de este modo se convierte en una fuente de investigación fundamental de la historia reciente.

Para poner disponibles las producciones online en la página web, habrá que tener en cuenta el posible acuerdo entre la Generalitat Valenciana y las productoras audiovisuales para recuperación de los derechos de emisión y paliar así la crisis desencadenada en el sector, según informaciones aparecidas en prensa recientemente. Lo cual concuerda con lo que dice la Unesco en su punto 6:

"La utilización de esas imágenes en movimiento no debería perjudicar los derechos legítimos ni los intereses de quienes intervienen en su producción y explotación, según lo estipulado en la Convención Universal sobre derecho de autor, el Convenio de Berna para la protección de las obras literarias y artísticas y la Convención Internacional sobre la protección de los artistas intérpretes o ejecutantes, los productores de fonogramas y los organismos de radiodifusión, y en la legislación nacional."

\section{4-Propuestas de futuro}

El archivo audiovisual de RTVV no tiene que ser necesariamente un archivo cerrado sino que podría ser el germen de un futuro centro consignatario del depósito legal de producciones audiovisuales de la Comunidad Valenciana.

Nuestra propuesta se basa tanto en la recomendaciones de la Unesco como en la ley 23/2011 de depósito legal y las leyes de patrimonio. Consiste fundamentalmente en que el archivo iniciado con la producción de Radiotelevisión valenciana ejerza de centro de conservación autonómico del depósito legal de los programas audiovisuales (no cinematográficos) producidos o emitidos en, para o desde la Comunidad Valenciana ya sean transmitidos por medios tangibles o intangibles. La ley establece que serán objeto del depósito legal "los programas audiovisuales emitidos por prestadores del servicio de comunicación audiovisual, salvo que sean objeto de distribución". A nuestro juicio, al ser RTVV un medio de comunicación que ha cesado sus emisiones no entra en conflicto con posibles derechos de distribución.

Igualmente, el futuro archivo audiovisual de la Comunidad Valenciana podría ser depositario de una copia de las producciones registradas con número ISAN (International Standard Audiovisual Number). El número ISAN, patrocinado por ISO y comparable al ISBN de las publicaciones impresas, se 
creó para identificar unívocamente programas de televisión, documentales, spots publicitarios, material promocional, videoclips, informativos, retransmisiones, deportivas, etc. a la vez que facilita la interoperabilidad y el intercambio de información. El ISAN contribuye a identificar a los autores de los derechos, a la catalogación eficaz y a la preservación del patrimonio audiovisual, al asignar un número de referencia unívoco para cada obra y para cada versión de la misma.

Aunque inicialmente se base en la custodia de emisiones televisivas producidas en, para o desde la Comunidad Valenciana, podría ampliarse en los siguientes puntos:

1. En la recepción de emisiones de cadenas locales de televisión de ámbito autonómico de la Comunidad Valenciana.

2.En la recepción de emisiones de cadenas locales de radiodifusión de ámbito autonómico de la Comunidad Valenciana.

3.En la recepción de series documentales, de ficción y otro tipo de producciones realizadas en, desde o para la Comunidad Valenciana y difundidas a través de Internet.

4.En la recepción de spots publicitarios realizados por empresas radicadas en la Comunidad Valenciana.

Los dos primeros puntos propuestos son acciones que desarrolla el INA Institut de l'Audiovisuel en Francia y no es descabellado pensar en reunir producciones de emisoras privadas, principalmente por dos motivos: porque la finalidad de estas empresas es comercial y no de conservación, y porque carecen en su mayoría de la infraestructura necesaria para poder llevar a cabo esta tarea.

También en Estados Unidos hay varios museos dedicados a la historia de la televisión, quizá el más conocido es el "Museo de la Televisión" creado por el presidente de la CBS W. Paley en 1975, un archivo histórico que contiene más de 100.00oprogramas de televisión, radio y spots publicitarios emitidos por todas las televisiones estadounidenses, permitiendo el acceso público para su consulta.

Para emprender un trabajo de esta envergadura sería deseable contar con el apoyo de un Consejo del Audiovisual (similar a los existentes en Navarra, Andalucía o Cataluña), como garante del cumplimiento de la normativa en la prestación de comunicación audiovisual en sus respectivos territorios además 
de ejercer la defensa de los ciudadanos como usuarios de estos servicios.

También se puede contar con el apoyo de las leyes para dar soporte a esta iniciativa. Por ejemplo, la Ley 22/2005 de la comunicación audiovisual de Cataluña establece la obligación para los prestadores de servicios de comunicación audiovisual de depositar una copia en soporte digital de cada uno de los programas y las obras de producción propia una vez se hayan difundido, sin perjuicio de la protección de los derechos relativos a la propiedad intelectual. Igualmente se garantiza la preservación del patrimonio digital mediante la obligación, a estos mismos prestadores de servicios, de digitalizar el patrimonio audiovisual mediante la tecnología digital o la que en el futuro pueda sustituirla.

También es posible obtener ingresos mediante la explotación comercial de los archivos. Se podrían elaborar productos documentales con todos los recursos de los que cuenta la Unidad de Documentación. Como ejemplos podríamos citar la evolución de parajes naturales, recopilaciones sobre valencianos que vivieron determinados hechos históricos (atentados del 11S, la caída del muro de Berlín,... ), monográficos sobre escritores o artistas, sobre sus obras, potenciando especialmente los contenidos educativos.

La página web podría dinamizarse a través de las redes sociales con la propuesta de juegos, concursos, proponiendo la identificación de personas que aparecen en las grabaciones y otras iniciativas de participación.

\section{5.-Conclusiones}

Con todas las acciones propuestas cumpliríamos el objetivo, no solo de custodiar el patrimonio audiovisual de Radiotelevisión Valenciana, sino de salvaguardar todo el patrimonio audiovisual valenciano, manteniendo el archivo vivo, explotando su valor comercial, y difundiendo sus contenidos a la vez que se protege y se garantiza la preservación para generaciones futuras. Compartimos la opinión de Edmondson (2004), para quien el acceso al patrimonio documental concuerda con la Declaración Universal de Derechos Humanos de las Naciones Unidas de 1948 y con el Pacto Internacional de Derechos Civiles y Políticos de 1966.

Podemos establecer una analogía entre los sistemas de información y los sistemas complejos estudiados por la Termodinámica. Si se aíslan tienden a la entropía máxima, es decir, al máximo desorden y, consecuentemente, a la muerte. Solo los sistemas abiertos, es decir, aquellos que intercambian materia, energía e información con su entorno, pueden mantener un alto grado de complejidad, es decir, comportarse como sistemas complejos vivientes. 


\section{6.-Referencias bibliográficas}

AGENCIA IBEROAMERICANA DEL REGISTRO ISAN (2006). [Sitio Web] [Consulta: 29-42014]. Disponible en:

$<$ www.aribsan.org/default_iberoamerica.asp >

ANDERSEN, K. E. (2005). Legal Deposit and access to broadcasting in Norway, The Riga

Seminar 15.10.2005 - Audiovisual Archives. [Consulta: 25-6-2014]. Disponible en:

<http://www.baacouncil.org/media/public/files/edg/

Legal_Deposit_and_access_tobroadcasting_in_Norway2.pdf >

BORRÁS, D. (2014). Cultura sale al rescate del sector más afectado por el cierre de Canal 9 con 7 millones en ayudas [en línea], El Mundo, 25 de marzo de 2014. [Consulta: 2-5-2014].

Disponible en

<http://www.elmundo.es/comunidad-

valenciana/2014/03/25/533096f4268e3eb72c8b458e.html>

BRITISH LIBRARY (2014).Report of the Working Party on Legal Deposit [en linea].[Consulta: 25-6-2014]. Disponible en:

<http://www.bl.uk/aboutus/stratpolprog/legaldep/report/\#Appendix C>

EDMONSON, R. (2004).Filosofía y principios de los archivos audiovisuales. París: Unesco..

[Consulta: 2-5-2014]. Disponible en:

<unesdoc.unesco.org/images/o013/o01364/136477s.pdf>

EDMONSON, R. (2009). Fundamentos filosóficos de los archivos audiovisuales en la era digital, La salvaguarda del patrimonio sonoro y audiovisual: un reto mundial. Memorias del cuarto seminario internacional de archivos sonoros y audiovisuales. México D.F: Fonoteca Nacional. [Consulta: 2-5-2014]. Disponible en:

<http://revistas.ucm.es/index.php/CDMU/article/download/38324/37079>

ESPAÑA.(2013). Borrador de proyecto de Real Decreto por el que se regula el depósito legal de las publicaciones electrónicas [en línea][Consultado en 2-5-2014]. Disponible en: <http://www.mecd.gob.es/servicios-al-ciudadano-mecd/participacion-publica/ cerrados/2013/dl-publicaciones-electronicas.html>

ESPAÑA (2005). Ley 22/2005, de 29 de diciembre, de la comunicación audiovisual de Cataluña, Boletín Oficial del Estado, 14 de febrero de 2006, No.38, pp.5746-5777. [Consulta: 25-2014]. Disponible en:

<http://www.boe.es/boe/dias/2006/02/14/pdfs/A05746-05777.pdf>

ESPAÑA (2006). Ley 17/2006, de 5 de junio, de la Radio y Televisión de titularidad estatal, Boletín Oficial del Estado, 6 de junio de 2006, No.134, pp.21307-21218. [Consulta: 2-5-2014]. Disponible en:

<www.boe.es/boe/dias/2006/o6/o6/pdfs/A21207-21218.pdf>

ESPAÑA (2010). Ley 7/2010 General, de 31 de marzo, de Comunicación Audiovisual, Boletín Oficial del Estado, 1 de abril de 2010, No.79, pp.30157-30209. [Consulta: 2-5-2014].

Disponible en:

<http://www.boe.es/boe/dias/2010/04/o1/pdfs/BOE-A-2010-5292.pdf>

ESPAÑA (2011). Ley 23/2011, de 29 de julio, de depósito legal. Boletín Oficial del Estado, 30 de julio de 2011, No.182, pp.86716-86727. [Consultado: 6-5-2014]. Disponible en:7 <www.boe.es/boe/dias/2011/o7/30/pdfs/BOE-A-2011-13114.pdf > 
FRANCIA (2014).Code du patrimoine.Versionconsolidéeau 30 mai 2014. [Consultado: 25-62014]. Disponible en:

<http://www.legifrance.gouv.fr/affichCode.do?cidTexte=LEGITEXTooooo6074236>

GRAN BRETAÑA. (2014)BroadcastingAct 1990.[Consulta: 25-6-2014]. Disponible en: <http://www.legislation.gov.uk/ukpga/1990/42/contents>

HERNÁNDEZ-PÉREZ, T. y CARIDAD-SEBASTIÁN, M. (2011). Preservación y digitalización de la documentación audiovisual”, Documentación audiovisual. Madrid: Síntesis

HIDALGO-GOYANES, P. (1999). Documentación audiovisual, en García-Gutiérrez, A. (Ed.), Introducción a la Documentación Informativa y Periodística.Sevilla: MAD, pp.473-485

HIDALGO-GOYANES, P. (2013). Prevenir la amnesia colectiva: El acceso público a los archivos de televisión, Documentación de las Ciencias de la Información, Vol.36, pp.143-166. [Consulta: 25-6-2014]. Disponible en:

<http://revistas.ucm.es/index.php/DCIN/article/view/42946>

INA,INSTITUT NATIONAL DE L'AUDIOVISUEL. [Consulta: el 25-6-2014]. Disponible en: $<$ www.institut-national-audiovisuel.fr/nous-connaitre/entreprise/index.html>

Informations sur l'élaboration de la loi sur l'encouragement de la culture LEC et le message culture 2012-2015.[Consulta: 25-6-2014]. Disponible en:

<http://fr.memoriav.ch/av/judicial/lec.aspx>

IIPC, International Internet Preservation Consortium. Legaldeposit. [Consulta: el 25-6-2014]. Disponible en:

<http://netpreserve.org/legal-deposit>

ISAN (International Standard Audiovisual Number) (2013).[Consulta: 29-4-2014]. Disponible en:

<http://www.isan.org/>

LIBRARY AND ARCHIVES CANADA.Managing Audio-Visual Records in the Government of Canada.[Consulta: 25-6-2014]. Disponible en:

<http://collectionscanada.ca/government/002/007002-2049-e.html>

LÓPEZ-DE-SOLÍS, I. y MARTÍN-LÓPEZ, C. (2011). Nuevas estrategias de negocio y valorización de los archivos audiovisuales en internet, El profesional de la información, noviembre-diciembre, Vol.20, No.6, pp.659-666. [Consulta: 2-5-2014]. Disponible en: <http://dx.doi.org/10.3145/epi.2011.nov.09>

MEMORIAV. [Sitio web]. [Consulta: 25-6-2014]. Disponible en: $<$ http://fr.memoriav.ch/>

RONCO-LÓPEZ, Ma M. (2009). Los documentos audiovisuales y su conservación, Los servicios de documentación de los medios de comunicación del País Vasco, Bilbao:

Universidad del País Vasco, pp.73-100

SALVADOR-BENÍTEZ, A. (2010). Políticas de salvaguardia y acceso en los archivos audiovisuales de televisión. Marco jurídico y nuevos servicios interactivos en la televisión digital, Derecom, No.2. [Consulta: 2-5-2014]. Disponible en:

$<$ http://derecom.com/numeros/pdf/salvador.pdf $>$ 
MEI, II, Vol. 5, no 8, pág. 42

SLBA, Swedish National Archive of Recorded Sound and Moving Images. [Consulta: 25-62014]. Disponible en:

<http://videoactive.wordpress.com/the-consortium/swedish-national-archive/>

Television in the Library of Congress.1989. [Consulta: 25-6-2014]. Disponible en:

$<$ www.loc.gov/rr/mopic/tvcoll.html>

UNESCO (1980), Recomendaciones para la salvaguardia y la conservación de las imágenes en movimiento. París: Unesco.[Consulta: 2-5-2014]. Disponible en:

$<$ http://unesdoc.unesco.org/images/o011/o01140/114029s.pdf >

UNESCO (2002).Memoria del mundo: Directrices para la salvaguardia del patrimonio documental. París: Unesco,.[Consulta: 2-5-2014]. Disponible en:

<http://unesdoc.unesco.org/images/o012/001256/125637s.pdf> 